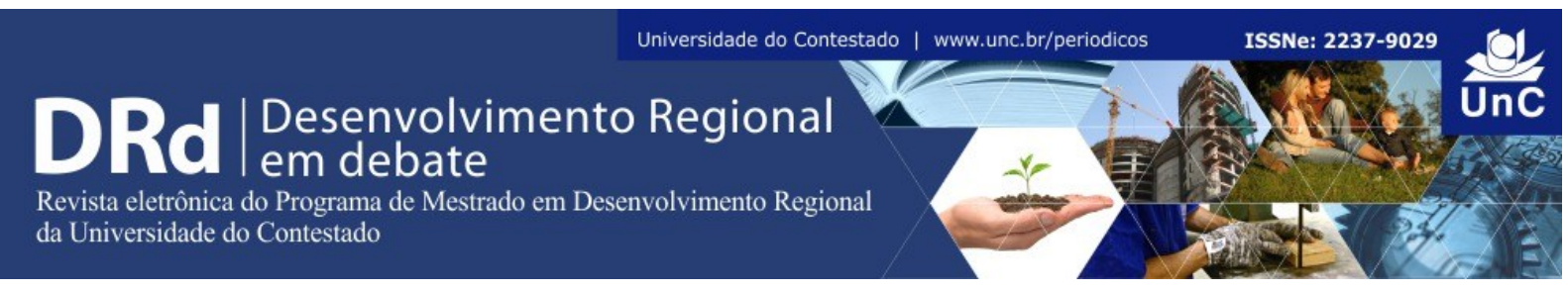

\title{
PRODUTO INTERNO BRUTO (PIB) VERSUS ÍNDICE DE DESENVOLVIMENTO HUMANO MUNICIPAL (IDHM) NA MICRORREGIÃO DE DOURADOS/MS
}

\author{
Vilmar Nogueira Duarte ${ }^{1}$ \\ Karoline Almeida Cavalcanti ${ }^{2}$
}

\begin{abstract}
RESUMO
Esta pesquisa objetivou identificar a relação entre a variação do Produto Interno Bruto (PIB) e a variação do Índice de Desenvolvimento Humano Municipal (IDHM) dos municípios da microrregião de Dourados, em Mato Grosso do Sul, no período de 2000 a 2010. O trabalho foi realizado com base num estudo descritivo e exploratório, elaborado a partir de material já publicado. Os dados foram obtidos junto a Secretaria de Estado do Meio Ambiente, do Planejamento, da Ciência e Tecnologia - SEMAC/MS, e no site do Programa das Nações Unidas para o Desenvolvimento - PNUD. Os resultados indicaram que o município de Dourados responde pela maior parcela do PIB regional, cujo percentual foi de $40,6 \%$ em 2010. Apontaram ainda, que embora todos os municípios estudados tenham aumentado seus respectivos PIBs no período, alguns diminuíram suas participações relativas no PIB total da microrregião. Com relação ao IDHM, todos apresentaram aumento de 2000 para 2010, com a longevidade e a renda média contribuindo com as maiores parcelas do IDHM em todos os casos. Por fim, conclui-se que o desenvolvimento dos municípios da microrregião de Dourados, medido pelo IDHM, parece não ter relação com o nível de crescimento econômico desses municípios, uma vez que o quesito educação, o qual apresentou índices abaixo da média nacional, foi determinante no resultado do IDHM no período. O que permite afirmar não existir, na microrregião estudada, uma relação causal entre crescimento econômico e melhoria das condições de vida das pessoas.
\end{abstract}

Palavras-chave: Produto Interno Bruto. Índice de Desenvolvimento Humano Municipal. Microrregião de Dourados.

\section{GROSS DOMESTIC PRODUCT (GDP) VERSUS MUNICIPAL HUMAN DEVELOPMENT INDEX (MHDI) IN THE MICROREGION OF DOURADOS/MS}

\begin{abstract}
This research aimed to identify the relationship between growth in gross domestic product (GDP) and the variation of the Municipal Human Development Index (MHDI) of the microregion of Dourados in Mato Grosso do Sul, from 2000 to 2010. The work was carried out from a descriptive and exploratory analysis, led from already published material. Data were obtained from the Secretary of State for the Environment, Planning, Science and Technology -

\footnotetext{
${ }^{1}$ Universidade Estadual do Mato Grosso do Sul (MS). Mato Grosso do Sul. Brasil. E-mail: vilmarufms@yahoo.com.br

${ }^{2}$ Universidade Estadual do Mato Grosso do Sul (MS). Mato Grosso do Sul. Brasil. E-mail: karolcavalcanti@hotmail.com
}

DRd - Desenvolvimento Regional em debate (ISSNe 2237-9029)

v. 6 , n. 1, p. 120-135, jan./jul. 2016. 
SEMAC/MS, and the site of the United Nations Development Programme - UNDP. The results indicated that the city of Dourados is responsible for the largest share of regional GDP, whose percentage was $40.6 \%$ in 2010 . They also indicated, that although all the cities studied have increased their GDP in the period, some of them have decreased their relative shares in the total GDP of the micro-region. Regarding MHDI, all cities show increase from 2000 to 2010, with the longevity and the average income contributing the largest MHDI installments in all cases. Finally, it is concluded that the development of the micro-region of Dourados, as measured by MHDI, seems to have no relationship with the level of economic growth in these municipalities, since the question education, which had rates below the national average, was decisive in the result of MHDI in such period. What allows us to say that there is not, in the studied microregion a causal relationship between economic growth and improvement of people's lives.

Key words: Gross Domestic Product. Municipal Human Development Index. Micro Dourados.

\section{INTRODUÇÃO}

A teoria econômica, em alguns casos, tem dado ênfase ao crescimento como sendo sinônimo de desenvolvimento, ressaltando que o incremento da renda é uma condição necessária para o desenvolvimento sem se preocupar, no entanto, em como os frutos desse crescimento estão sendo distribuídos entre os diferentes segmentos sociais. Todavia, existe outro grupo de autores mais voltados para a realidade empírica, para os quais o crescimento por si só não é suficiente para sustentar o desenvolvimento, uma vez que este último requer mudanças qualitativas na vida das pessoas, das instituições e das estruturas produtivas (SOUZA, 2007).

Sabe-se que o crescimento econômico pode ser medido pelo volume de produção que a economia de uma dada região é capaz de gerar em determinado período. Contudo, esse crescimento não faz sentido se não promover o desenvolvimento humano, entendido como sendo a razão maior dos indivíduos. Dessa forma, o paradigma do desenvolvimento passa a ter o ser humano como o fim e o crescimento econômico como o meio. Assim, confrontar os níveis de crescimento econômico com os níveis de desenvolvimento humano, em dado período, se justifica no sentido de avaliar se de fato os benefícios do primeiro estão sendo distribuídos adequadamente entre a população de modo geral, e se o número de pessoas pobres está sendo reduzido.

Neste contexto, partindo do pressuposto de que os municípios da microrregião de Dourados, no estado de Mato Grosso do Sul, tenham apresentado alterações nos seus indicadores de crescimento e de desenvolvimento econômico no período de 2000 a 2010, o presente estudo teve como objetivo verificar se houve relação entre a variação do Produto Interno Bruto (PIB) e a variação do Índice de Desenvolvimento Humano Municipal (IDHM) dos municípios da microrregião no período. Para isso, utilizou-se de um estudo descritivo, o qual possibilitou comparar a evolução dos IDHs municipais com as variações de seus respectivos PIBs no período em questão. A participação dos componentes, educação, 
longevidade e renda média da população, assim como a evolução destes, também foram objetos de discussão aqui.

Entre os trabalhos que abordam as questões relacionadas ao crescimento e ao desenvolvimento econômico e social destacam-se os realizados por Myrdal (1957), Lewis (1960), Furtado (1961), Furtado (1967), Simonsen (1975), Oliveira (2002), Souza (2007), Souza (2009), Feijó (2007), Bassan (2014), entre outros.

Este artigo apresenta cinco seções. Além da introdutória, apresenta um quadro teórico sobre a importância do crescimento para o desenvolvimento econômico e social, bem como os indicadores utilizados para medi-lo, a metodologia utilizada na pesquisa, a análise dos resultados e, por fim, as considerações finais.

\section{CRESCIMENTO E DESENVOLVIMENTO ECONÔMICO}

A importância do crescimento para o desenvolvimento econômico tem sido bastante discutida no meio acadêmico. São muitos os autores que abordam o tema em seus trabalhos, ampliando a discussão e enriquecendo a teoria com seus pontos de vista. Lewis (1960) considera importante o crescimento para alcançar o desenvolvimento, isso porque permite uma maior liberdade de escolha de como melhor aproveitar o tempo. O mesmo autor ressalta que graças ao crescimento é possível fazer escolhas, reservando mais tempo para o lazer ou mais tempo para a produção de bens e serviços.

Para Simonsen (1975), o desenvolvimento econômico só pode ser alcançado a partir de uma participação mais efetiva do Estado na atividade econômica. Defende o protecionismo econômico, a disponibilidade de crédito barato e também programas de substituição de importações.

Furtado (1961) ao se referir à importância do Estado na economia, argumenta que este objetiva melhorar a distribuição regional e setorial dos investimentos, promover uma melhor distribuição de renda no intuito de ampliar o mercado interno, controlar a entrada de capital estrangeiro no país, reduzir a dependência financeira externa oferecendo maior autonomia na execução das politicas públicas. Ainda de acordo com Furtado (1967), o melhor indicador de desenvolvimento é o aumento do fluxo de renda por unidade de trabalho, como pregava a teoria clássica. Para ele, o desenvolvimento está inteiramente condicionado ao aumento da produção e da produtividade com consequente distribuição de renda, fatores considerados essenciais para o incremento da demanda.

Já para Sandroni (1994), o desenvolvimento é entendido como sendo um processo de crescimento que é acompanhado de alterações estruturais na economia. O qual depende das características de cada país ou região, da sua história econômica, da posição e extensão geográficas, das condições demográficas, da cultura e dos recursos naturais existentes. Bassan (2014) acompanha este pensamento reforçando a ideia de que o desenvolvimento está relacionado a um processo de transformação na estrutura econômica, mas ressalta que este deve resultar em melhorias na área social. 
Seguindo essa mesma linha de raciocínio, Siedenberg (2006) argumenta que o crescimento econômico está relacionado a mudanças de caráter quantitativo, significando aumento em dimensão, volume e/ou quantidade. Porém, se esse crescimento resultar em melhoria dos indicadores sociais, então pode ser tratado como desenvolvimento. Nestes termos, o desenvolvimento é um processo de mudanças tanto econômicas quanto sociais que ocorrem em determinada região. Reflexão esta que também é compartilhada por Vasconcellos (2000), em que o autor afirma que o desenvolvimento é um conceito de ordem mais qualitativa do que o de crescimento econômico, uma vez que reflete indicadores de bem-estar social, como condições de saúde, nutrição, educação, segurança pública, moradia, acesso à informação, entre outros.

Souza (2007) referindo-se à questão do desenvolvimento ressalta que este requer um ritmo de crescimento econômico contínuo, porém há taxas maiores que a do crescimento demográfico. $\mathrm{O}$ autor enfatiza ainda que esse crescimento além de acompanhado de alterações na estrutura econômica, como já mencionado, deve vir acompanhado também de melhoria nos indicadores de qualidade de vida das pessoas. Neste sentido, o crescimento aparece, portanto, como condicionante importante para impulsionar o desenvolvimento. Contudo, este último deve ser encarado como um processo complexo de mudanças e transformações de ordem econômica, política e, sobretudo, social.

Feijó (2007, p. 44) ao se referir a essa problemática, considera que "além de crescimento econômico, o desenvolvimento requer políticas públicas e ações privadas que possam espalhar os benefícios do crescimento, alcançando um número maior de pessoas". Para o autor, a noção de desenvolvimento econômico deve funcionar como um critério para avaliar se as políticas indutoras de crescimento, acompanhadas de iniciativas de suporte social, atingem, de fato, os objetivos predeterminados.

Na visão de Oliveira (2002), o desenvolvimento é resultado, em qualquer concepção, do crescimento econômico acompanhado de melhorias no padrão de vida da população em geral. Significando, em outros termos, que os recursos disponíveis na economia devem ser alocados com o intuito de promover o bem-estar comum. Neste contexto, é importante que se olhe na direção de uma economia social, ou seja, uma economia a serviço de todos e que priorize as pessoas.

Gadotti (2000) enfatiza que o ser humano deve ser o alvo principal no processo de desenvolvimento. O que significaria, em outras palavras, passar de um conceito meramente econômico, que leva em conta apenas os ganhos de produtividade, melhoria da estrutura de produção, economia de escala e outros, para um conceito mais amplo que contemple a redução da exclusão social, caracterizada pela pobreza e pela desigualdade. Ademais, ressaltase ainda, que essa noção de desenvolvimento só tem sentido se ocorrer de forma abrangente, contínua e sustentável, ou seja, atingindo um número cada vez maior de pessoas e elevando seu padrão de vida ao longo do tempo.

Como se observa, o debate a cerca da noção de desenvolvimento é acirrado. Assim sendo, percebe-se a necessidade de se elaborar modelos de desenvolvimento que comtemplem o maior número de variáveis econômicas e sociais possível. O objetivo final da análise deve ser o de entender de que forma o bem-estar social se espalha pela população. Nesse caso, o desenvolvimento humano deve estar acima de qualquer outro objetivo e, por isso, a inclusão social deve estar na pauta das discussões. Só assim pode-se dar direção ao propósito final do 
desenvolvimento econômico, que é o desenvolvimento das pessoas, permitindo que estas desfrutem de uma boa saúde, educação e moradia digna para usufruir de uma longa vida produtiva, melhorando os indicadores sociais, reduzindo a pobreza e as desigualdades.

\subsection{DESENVOLVIMENTO ECONÔMICO NA ESFERA REGIONAL}

A teoria nos ensina que o próprio processo de desenvolvimento promove desigualdades econômicas e regionais em um país, criando economias externas favoráveis à sua continuidade. A expansão de uma determinada região tende a produzir efeitos regressivos em outras. Entre esses efeitos estão: a migração da população mais jovem em idade apta para o trabalho, bem como de profissionais técnico mais qualificado; o movimento de capital em busca de taxas de retornos mais elevadas; e o comércio que se desloca para as áreas centrais em busca de maior contingente de demanda. Estes são, sem dúvida, os meios pelos quais o processo de acumulação de capital se desenvolve para cima nas regiões mais desenvolvidas, e para baixo nas mais pobres (MYRDAL, 1957).

Além da evasão de capitais e de trabalhadores, é necessário entender que as regiões menos desenvolvidas apresentam sérias deficiências estruturais, como é o caso, por exemplo, de portos, ferrovias, rodovias, aeroportos, energia, comunicações, escolas técnicas, hospitais, centros de pesquisas e outros serviços públicos básicos. Ademais, os impactos dos efeitos regressivos tendem a aumentar com as trocas desiguais. Isso se deve ao fato das regiões mais ricas exportarem produtos manufaturados de maior valor agregado para as regiões mais pobres, enquanto que estas são exportadoras apenas de matérias-primas e alimentos não processados cujos preços, segundo Souza (2009), além de inferiores, tendem a apresentar oscilações significativas de um período para outro.

Outra questão que deve ser levada em consideração, é que o fenômeno da concentração de renda se deve também ao fato das regiões mais desenvolvidas contarem com um setor industrial forte, com empresas detentoras de tecnologias de última geração e alta relação capital/trabalho, enquanto que as mais pobres, além de serem menos industrializadas, contam com empresas mais tradicionais, que dispõem de tecnologias relativamente mais antigas e mão de obra intensiva e de baixa qualificação. Além disso, as regiões menos desenvolvidas enfrentam ainda problemas de restrições orçamentárias, as quais inibem o investimento público em setores estratégicos e na área social, explicando o reduzido crescimento econômico e os pontos de estrangulamento e pobreza existentes (SOUZA, 2007).

De qualquer forma, percebe-se que as áreas mais dinâmicas atraem os fatores de produção e crescem mais rapidamente, enquanto que aquelas com problemas estruturais perdem população e capital financeiro (SOUZA, 2009). Para o autor, as disparidades regionais se agravam com o crescimento desigual das mesmas, independente onde o analista coloca as suas fronteiras. Os estudos regionais em geral, de acordo com sua análise, têm sido efetuados em termos comparativos com outras regiões e em relação à economia nacional, enfatizando que o desempenho do conjunto das regiões é um parâmetro fundamental de comparação, principalmente nos estudos que visam entender o desempenho de cada região em relação às demais. Ressalta ainda que a determinação dos mecanismos que causam e aceleram as disparidades espaciais é de fundamental importância para a análise de estudos regionais.

DRd - Desenvolvimento Regional em debate (ISSNe 2237-9029) 


\subsection{INDICADORES DE DESENVOLVIMENTO ECONÔMICO}

O nível de desenvolvimento econômico e social de uma região é usualmente medido pelo Índice de Desenvolvimento Humano Municipal (IDHM), criado pelo Programa das Nações Unidas para o Desenvolvimento (PNUD). É utilizado para medir o desenvolvimento de países, estados, regiões e municípios. Trata-se de um índice que varia de 0 (nenhum desenvolvimento humano) a 1(desenvolvimento humano total). Está dividido em cinco categorias: desenvolvimento humano muito baixo (IDHM $\leq 0,499$ ); desenvolvimento humano baixo $(0,500 \leq \mathrm{IDHM} \leq 0,599)$; desenvolvimento humano médio $(0,600 \leq \mathrm{IDHM} \leq 0,699)$; desenvolvimento humano alto $(0,700 \leq \mathrm{IDHM} \leq 0,799)$; e desenvolvimento humano muito alto (IDHM $\geq 0,800$ ). Esse índice é calculado levando-se em conta três dimensões: educação, longevidade e renda. Quanto melhor o desempenho municipal em qualquer uma dessas dimensões, mais próximo de um $(1,0)$ será o índice. O IDHM é considerado o índice mais apropriado para avaliar as condições de pequenos grupos sociais (PNUD, 2015).

O cálculo do IDHM é feito de acordo com a seguinte lógica: para a avaliação da dimensão educação, são levados em consideração dois indicadores com pesos diferentes: taxa de alfabetização de pessoas acima de 15 anos (com peso dois) e a taxa bruta de frequência à escola (com peso um). O primeiro indicador significa o percentual de pessoas com mais de 15 anos capaz de ler e escrever um bilhete simples, ou seja, adultos alfabetizados. O segundo é resultado de uma conta que envolve a somatória de pessoas, independente da idade, que frequentam os cursos de ensino fundamental, médio e superior, dividido pela população local com idade entre 7 a 22 anos. Lembrando que estão incluídos nesta conta os alunos de cursos supletivos de ensino fundamental e médio, de classes de aceleração e de pós-graduação universitária.

Para a avaliação da dimensão longevidade, o IDHM leva em consideração o mesmo indicador do IDH de países, que é a esperança de vida ao nascer. Esse número indica o número médio de anos que uma pessoa nascida naquela localidade deve viver. $\mathrm{O}$ indicador longevidade sintetiza as condições de saúde e salubridade naquele local. Todas as causas de morte são contempladas para chegar ao indicador, tanto aquelas ocorridas em função de doenças quanto às provocadas por causas externas, como violências, acidentes e outros. Isso significa que quanto mais mortes houver nas faixas iniciais da vida, menor tende a ser a expectativa de vida observada no local.

No que se refere à dimensão da renda, o critério utilizado para o cálculo é o da renda municipal per capita, ou seja, a renda média de cada residente no município. Esse valor é encontrado através da soma da renda de todos os residentes, dividido pelo número de pessoas que moram no município, inclusive crianças e pessoas com renda igual a zero. No caso brasileiro, essa renda é calculada a partir das respostas ao questionário expandido do Censo do IBGE. De posse desses dados, são somadas todas as rendas obtidas pelos moradores do município, incluindo salários, pensões, aposentadorias, transferências governamentais, entre outros, e dividido pelo número de habitantes. Como resultado tem-se a renda municipal per capita. 


\section{ASPECTOS METODOLÓGICOS}

O estudo foi realizado com base numa pesquisa descritiva e exploratória, elaborada a partir de informações já publicadas. Pesquisas dessa natureza são habitualmente as mais usadas pelos pesquisadores sociais, devido à facilidade de sua aplicação prática e por permitir o estabelecimento de relações entre as variáveis (GIL, 2002).

A análise foi realizada da seguinte forma: primeiramente comparou-se a participação dos respectivos PIBs municipais em relação ao PIB total da microrregião, no período compreendido entre 2000 e 2010, ressaltando a evolução da participação dos setores agropecuário, industrial e de comércio e serviços de cada município no período. Em seguida, comparou-se a evolução do IDHM total em relação à evolução do PIB de cada município e também a evolução de cada componente, educação, longevidade e renda média da população de 2000 a 2010.

As informações sobre IDHM dos municípios foram obtidas junto ao site do Programa das Nações Unidas para o Desenvolvimento - PNUD. Já as informações relacionadas aos PIBs municipais, bem como sobre os PIBs dos setores econômicos, foram obtidas a partir de dados da Secretaria de Estado de Meio Ambiente, do Planejamento, da Ciência e Tecnologia - SEMAC do estado de Mato Grosso do Sul.

\section{ANÁLISE DOS RESULTADOS}

Localizada na região Sudeste de Mato Grosso do Sul, a microrregião de Dourados compõe-se de quinze municípios, distribuídos em um território de aproximadamente 37.360 $\mathrm{Km}^{2}$. É a segunda maior microrregião do estado em termos de riqueza, tendo sido responsável por 20,5\% do Valor Adicionado ao PIB sul-mato-grossense em 2010. Tem como destaques os polos econômicos de Dourados (centro agroindustrial) e de Ponta Porã (centro de comércio e de serviços). O município de Dourados é o principal centro econômico da microrregião, o qual representou 40,62\% do PIB total da microrregião e $8,14 \%$ do PIB estadual em 2010 (SEMAC/MS, 2010).

No que se refere ao perfil econômico dos municípios que abrangem a microrregião de Dourados, pelo peso das atividades econômicas, o município de Dourados concentra elevada participação em relação aos demais municípios em todos os setores, com destaque para a importância do setor industrial (Tabela 1). Embora o peso do setor de comércio e de serviços tivesse representado pouco menos da metade do valor adicionado ao PIB da microrregião em 2010, verifica-se que em relação à participação do PIB municipal no mesmo ano, esse percentual foi de 72,8\% (SEMAC/MS, 2010).

A importância do município de Dourados, ainda que seja relativamente grande em relação à microrregião, teve sua participação reduzida em todos os setores no período analisado. Em 2000, a indústria era considerada o setor de maior relevância com 55,75\% de participação, seguido do de comércio e serviços com 50,48\%, e da agropecuária com seu 
menor índice participativo no ano, 15,73\%. Em 2010, com perda percentual em todos os setores, o município de Dourados apresentou maior participação do setor de comércio e serviços, $47,2 \%$, com a indústria contribuindo com $46,48 \%$ do PIB da microrregião e a atividade agropecuária com $11,36 \%$ (Tabela 1$)$.

O município de Rio Brilhante destaca-se na agropecuária, impulsionado, principalmente, pelo incremento produtivo da cana-de-açúcar que elevou a participação do setor primário do município em relação à microrregião de 11,49\% em 2000, para 19,21 em 2010. Embora o setor industrial tivesse apresentado menor participação no PIB da microrregião em 2000, 4,63\%, este apresentou expansão de $168 \%$, passando para $12,41 \%$ em 2010 (Tabela 1). Assim, a participação do município de Rio Brilhante no PIB da microrregião foi de 9,65\% em 2010, ficando atrás apenas dos municípios de Dourados, Ponta Porã e Maracaju, que no mesmo ano, apresentaram participação no PIB regional de 40,62\%, 11,10\% e 10,39\%, respectivamente (SEMAC/MS, 2010).

Tabela 1 - Perfil da economia regional pelo peso das atividades econômicas de cada município sobre a microrregião de 2000 e 2010 (em \%).

\begin{tabular}{lrr|rr|rr}
\hline SETORES & \multicolumn{2}{c|}{ AGROP. } & \multicolumn{2}{c|}{ INDÚST. } & \multicolumn{2}{c}{ COM. E SERV. } \\
\hline MUNICÍPIOS & 2000 & 2010 & 2000 & 2010 & 2000 & 2010 \\
\hline Amambai & 5,42 & 5,43 & 7,35 & 3,06 & 2,25 & 4,63 \\
Antônio João & 1,67 & 1,50 & 0,46 & 0,65 & 1,04 & 2,24 \\
Aral Moreira & 6,48 & 4,71 & 0,49 & 0,69 & 1,79 & 2,12 \\
Caarapó & 7,85 & 6,88 & 6,25 & 7,56 & 3,82 & 4,74 \\
Douradina & 1,15 & 0,78 & 0,37 & 0,41 & 0,91 & 0,71 \\
Dourados & 15,73 & 11,36 & 55,75 & 46,48 & 50,48 & 47,27 \\
Fátima do Sul & 1,30 & 0,79 & 1,73 & 1,47 & 3,23 & 2,79 \\
Itaporã & 5,70 & 4,24 & 5,19 & 2,89 & 3,19 & 3,40 \\
Juti & 1,81 & 2,66 & 0,53 & 0,34 & 0,70 & 0,75 \\
Laguna Carapã & 4,75 & 5,03 & 0,32 & 0,52 & 1,27 & 1,23 \\
Maracaju & 16,07 & 17,05 & 5,83 & 7,65 & 7,89 & 8,90 \\
Nova Alvorada do Sul & 5,52 & 8,48 & 2,95 & 4,86 & 1,91 & 2,57 \\
Ponta Porã & 14,11 & 10,86 & 7,83 & 9,84 & 14,16 & 11,75 \\
Rio Brilhante & 11,49 & 19,21 & 4,63 & 12,41 & 6,75 & 6,14 \\
Vicentina & 0,96 & 1,03 & 0,33 & 1,18 & 0,62 & 0,78 \\
\hline
\end{tabular}

Fonte: SEMAC/MS - Série histórica do PIB municipal 1999-2010.

Dos quinze municípios que compõem a microrregião de Dourados, os cinco de maior participação no valor adicionado ao PIB da região em 2010 foram: Dourados (em primeiro lugar) com 40,62\%, seguido de Ponta Porã com 11,1\%, Maracaju com 10,39\%, Rio Brilhante com 9,65\%, e Caarapó com 5,60\%. Com relação aos municípios de menor participação no PIB regional, aparecem Douradina com $0,63 \%$, Vicentina com $0,88 \%$ e o município de Juti cuja participação foi de $1,01 \%$ em 2010. Sendo este último caracterizado pela forte participação do setor agropecuário na composição das riquezas municipais (Tabela 1). 


\subsection{EVOLUÇÃO DO PIB E DO IDHM NOS MUNICÍPIOS DA MICRORREGIÃO DE DOURADOS}

Assim como foi descrito no tópico anterior, o município de Dourados apresentou a maior parcela participativa no PIB da microrregião. Da mesma forma, detém valores maiores para o índice de IDHM. É importante ressaltar, que embora o município tenha reduzido sua participação no PIB da microrregião entre o período de 2000 a 2010, de acordo com dados da SEMAC/MS de 2010, este teve sua produção expandida em $246,4 \%$ no período, enquanto que o IDHM cresceu apenas 17,45\%, como mostra a Tabela 2.

Por outro lado, observa-se que os municípios com pouca participação na produção da microrregião, como é o caso de Vicentina e Fátima do Sul, apresentaram IDHM superior a 0,700 em 2010. Esses municípios tiveram aumento do IDHM de 19,7\% e 19,8\%, respectivamente de 2000 a 2010. É importante observar que em 2010 seis municípios apresentaram IDHM superior a 0,700 (índice considerado alto), sendo que em 2000 apenas dois estavam acima de 0,599 (índice considerado médio), com Juti abaixo, com 0,480 (índice considerado muito baixo) (Tabela 2).

De modo geral, é perceptível, por meio dos dados da Tabela 2, que os municípios que compõem a microrregião de Dourados apresentaram significativos aumentos nos seus respectivos IDHMs, independente do tamanho de suas economias e de suas participações na economia regional. Por outro lado, a evolução dos IDHs municipais parece não ter relação com o setor econômico predominante em cada município, pelo menos foi o que se observou no período, levando em consideração as peculiaridades inerentes à região e a cada município em particular.

Tabela 2 - Participação do PIB dos municípios no PIB regional e IDHM por município entre 2000 e 2010.

\begin{tabular}{l|rr|cr}
\hline \multirow{2}{*}{ Municípios } & \multicolumn{2}{|c|}{ PIB de Mercado } & \multicolumn{2}{c}{ IDHM } \\
\cline { 2 - 5 } & 2000 & 2010 & 2000 & 2010 \\
\hline Amambai & 5,41 & 4,35 & 0,576 & 0,673 \\
Antônio João & 0,99 & 1,95 & 0,509 & 0,643 \\
Aral Moreira & 2,57 & 2,43 & 0,520 & 0,633 \\
Caarapó & 4,94 & 5,60 & 0,548 & 0,692 \\
Douradina & 0,84 & 0,63 & 0,567 & 0,699 \\
Dourados & 43,20 & 40,62 & 0,636 & 0,747 \\
Fátima do Sul & 2,35 & 2,06 & 0,596 & 0,714 \\
Itaporã & 3,89 & 3,46 & 0,550 & 0,654 \\
Juti & 0,87 & 1,01 & 0,480 & 0,623 \\
Laguna Carapã & 1,85 & 1,80 & 0,535 & 0,672 \\
Maracaju & 9,32 & 10,39 & 0,597 & 0,736 \\
Nova Alvorada do Sul & 2,85 & 4,09 & 0,539 & 0,694 \\
Ponta Porã & 12,86 & 11,10 & 0,600 & 0,701 \\
Rio Brilhante & 7,46 & 9,65 & 0,584 & 0,715 \\
Vicentina & 0,60 & 0,88 & 0,594 & 0,711 \\
\hline Font SEMAC/MS & $2010)$ PNUD
\end{tabular}


Quanto ao IDHM por componentes, constatou-se, por meio dos dados da Tabela 3, que a longevidade foi determinante na composição do IDH municipal no período estudado. Esse componente apresentou-se como o mais significativo na formação do índice, tanto no ano de 2000, quanto em 2010. Os municípios de Maracaju, Rio Brilhante e Dourados apresentaram os maiores índices de longevidade em 2010. Já em 2000, foram os municípios de Maracaju, Ponta Porã e Rio Brilhante. O quesito renda aparece em segundo lugar, em termos de participação no IDHM nos dois anos de referência. Já com a menor participação aparece o quesito educação, que embora tenha evoluído em todos os municípios da microrregião no período, ainda reflete uma média geral considerada bastante baixa, sobretudo, nos municípios de Juti, Aral Moreira, Antônio João, Amambai e Itaporã, os quais aparecem entre aqueles com problemas na educação.

Fazendo uma comparação com os dados ao nível de Brasil, percebeu-se que no quesito renda somente os municípios de Dourados, Maracaju e Nova Alvorada do Sul apresentaram índices superiores à média brasileira em 2010. Por outro lado, no ano de 2000, apenas Dourados superou a média. No que se refere à longevidade, em 2010 sete municípios detinham índices acima da média nacional, enquanto que em 2000 foram oito. Em relação à educação, Dourados e Fátima do Sul foram os únicos municípios a superar a média brasileira em 2000, enquanto que no ano de 2010, somente Dourados apresentou índice superior (Tabela $3)$.

Desse modo, ficou claro, a partir dos dados apresentados aqui, que os Índices de Desenvolvimento Humano Municipal (IDHMs) dos municípios da microrregião de Dourados parecem não estarem associados ao tamanho de seus respectivos PIBs. Pelos dados da Tabela 3 verifica-se que o quesito educação tem sido determinante para a composição do IDHM geral, restando saber quais motivos levam alguns municípios com perfil econômico tão semelhante apresentarem IDHM tão distintos.

Tabela 3 - Índice de desenvolvimento humano municipal por componente de 2000 e 2010.

\begin{tabular}{lccc|ccc}
\hline ANOS & \multicolumn{3}{c|}{2000} & \multicolumn{2}{c}{2010} \\
\hline Municípios & IDHM & $\begin{array}{c}\text { IDHM } \\
\text { Longevid. }\end{array}$ & $\begin{array}{c}\text { IDHM } \\
\text { Renda }\end{array}$ & $\begin{array}{c}\text { IDHM } \\
\text { Educ. }\end{array}$ & $\begin{array}{c}\text { IDH M } \\
\text { Longevid. }\end{array}$ & $\begin{array}{c}\text { IDHM } \\
\text { Renda }\end{array}$ \\
\hline Brasil & $\mathbf{0 , 4 5 6}$ & $\mathbf{0 , 7 2 7}$ & $\mathbf{0 , 6 9 2}$ & $\mathbf{0 , 6 3 7}$ & $\mathbf{0 , 8 1 6}$ & $\mathbf{0 , 7 3 9}$ \\
Amambai & 0,384 & 0,767 & 0,649 & 0,546 & 0,818 & 0,683 \\
Antônio João & 0,342 & 0,699 & 0,553 & 0,526 & 0,799 & 0,633 \\
Aral Moreira & 0,324 & 0,744 & 0,582 & 0,507 & 0,798 & 0,628 \\
Caarapó & 0,376 & 0,727 & 0,603 & 0,592 & 0,828 & 0,676 \\
Douradina & 0,406 & 0,723 & 0,622 & 0,597 & 0,809 & 0,706 \\
Dourados & 0,487 & 0,758 & 0,698 & 0,657 & 0,843 & 0,753 \\
Fátima do Sul & 0,459 & 0,719 & 0,641 & 0,621 & 0,815 & 0,719 \\
Itaporã & 0,378 & 0,712 & 0,617 & 0,523 & 0,809 & 0,660 \\
Juti & 0,269 & 0,712 & 0,577 & 0,485 & 0,770 & 0,646 \\
Laguna Carapã & 0,307 & 0,767 & 0,651 & 0,545 & 0,822 & 0,676 \\
Maracaju & 0,408 & 0,792 & 0,660 & 0,613 & 0,873 & 0,744 \\
Nova Alvorada do Sul & 0,331 & 0,723 & 0,655 & 0,554 & 0,809 & 0,746 \\
Ponta Porã & 0,416 & 0,774 & 0,670 & 0,598 & 0,812 & 0,708 \\
Rio Brilhante & 0,393 & 0,772 & 0,658 & 0,590 & 0,861 & 0,720 \\
Vicentina & 0,445 & 0,741 & 0,635 & 0,626 & 0,835 & 0,689 \\
\hline
\end{tabular}

Fonte: PNUD (2015). 
A título de exemplo, o município de Vicentina, que de acordo com dados da SEMAC/MS (2010) era o $71^{\circ}$ no ranking dos PIBs municipais do estado em 2010, aparece no mesmo ano com IDHM de 0,711 (Tabela 2). Com características bastante semelhantes aparece o município de Fátima do Sul, que segundo a SEMAC/MS (2010), estava em $44^{\circ}$ lugar no ranking e apresentava IDHM de 0,714 (Tabela 2). A semelhança entre esses municípios também está na contribuição do IDHM educação, que em Vicentina foi de 0,626 e em Fátima do Sul de 0,621 em 2010 (Tabela 3). Outra semelhança, é que a participação do setor industrial de nenhum destes municípios chegou a 1,5\% do PIB da microrregião em 2010, conforme mostra a Tabela 1 .

Em suma, os dados, aqui apresentados, mostraram que o desenvolvimento econômico, medido pelo Índice de Desenvolvimento Humano Municipal (IDHM), nem sempre esteve relacionado ao poder econômico do município em questão. Ressalta-se também, que os municípios que apresentaram IDHM elevado não necessariamente foram aqueles cujas economias são caracterizadas pela presença de um setor industrial forte. No caso dos municípios aqui estudados, apenas os quesitos longevidade e renda média alta não foram suficientes para sustentar um IDHM também elevado. O quesito educação foi determinante no resultado.

\subsection{APROFUNDANDO A ANÁLISE}

Ao desmembrar o PIB da microrregião por municípios, observou-se que Dourados tem grande influência na composição das riquezas regionais; seguido por Ponta Porã, Maracaju e Rio Brilhante, que juntos somaram quase um terço do PIB total da região em 2010. Os demais municípios apresentaram baixa participação individual na composição das riquezas da microrregião, conforme mostram os dados da Tabela 2. Essa supremacia de Dourados se deve, principalmente, à dinâmica de sua economia (centro agroindustrial da microrregião) com forte participação dos setores industrial e de comércio e serviços (Tabela 1).

Quanto aos municípios com menor participação, como é o caso, por exemplo, de Juti, Vicentina e Douradinha, o fato de serem relativamente pequenos, em relação a Dourados e a outros municípios, explica a pequena importância econômica destes para a microrregião. Além disso, suas economias são altamente dependentes do setor primário, com baixa participação dos demais setores. Por se tratarem de municípios de periferia, possuem pouca capacidade de criar setores dinâmicos como é o caso da indústria, do comércio e serviços. Por isso tendem a crescer menos em determinados períodos, já que apresentam alta dependência da agricultura e da pecuária, segmentos que são fortemente afetados por mudanças climáticas e por alterações na conjuntura econômica.

Vale ressaltar, que as cidades mais dinâmicas, como é o caso de Dourados, tornou-se o destino preferido de parte dos fatores de produção das regiões periféricas3, principalmente o capital, que migra em busca de retornos mais elevados, e a mão de obra, em especial a mais qualificada, que se desloca em busca de salários mais atraentes, gerando escassez desses fatores na periferia. Este é um fenômeno perverso que ocorre em todas as regiões, resultando

\footnotetext{
${ }^{3}$ Pequenos municípios localizados aos arredores da cidade de Dourados - MS
} 
em concentração dos fatores de produção nas cidades mais desenvolvidas. No estado de Mato Grosso do Sul as cidades de Campo Grande, Dourados e Três Lagoas têm sido as mais atrativas.

Quanto ao desenvolvimento dos municípios da microrregião, medido pelo Índice de Desenvolvimento Humano Municipal (IDHM), observa-se que todos os municípios apresentaram, em 2010, índices superiores a 0,600 e abaixo de 0,800, o que de acordo com a PNUD (2015) são índices que se enquadram nas categorias de desenvolvimento médio $(0,600$ $\leq \mathrm{IDHM} \leq 0,699)$ e alto $(0,700 \leq \mathrm{IDHM} \leq 0,799)$ numa escala de 0 a 1 . No entanto, embora de 2000 a 2010 nenhum município tenha atingido índice de desenvolvimento humano considerado muito alto (IDHM $\geq 0,800$ ), verificou-se que todos apresentaram evolução significativa no período, com Dourados alcançando índice de 0,747 e Maracaju 0,736, como mostra a Tabela 2.

A Figura 1 aponta o perfil dos municípios da microrregião em termos de evolução dos percentuais do PIB e do IDHM no período estudado, onde se percebe uma grande disparidade em termos de crescimento do PIB desses municípios e uma dispersão relativamente menor, porém ainda intensa em termos de crescimento de seus respectivos IDHMs. As maiores taxas de crescimento do PIB no período foram registradas nos municípios de Antônio João, Nova Alvorada do Sul e Vicentina, enquanto que em Amambai, Douradina e Ponta Porã registrouse os menores percentuais. Por outro lado, os municípios com maior evolução do IDHM foram Juti e Nova Alvorada do Sul, e os que menos evoluíram foram Amambai, Ponta Porã e Dourados (Figura 1).

Figura 1 - Crescimento do PIB e do IDHM nos municípios da microrregião no período de 2000 a 2010

$(\mathrm{em} \%)$

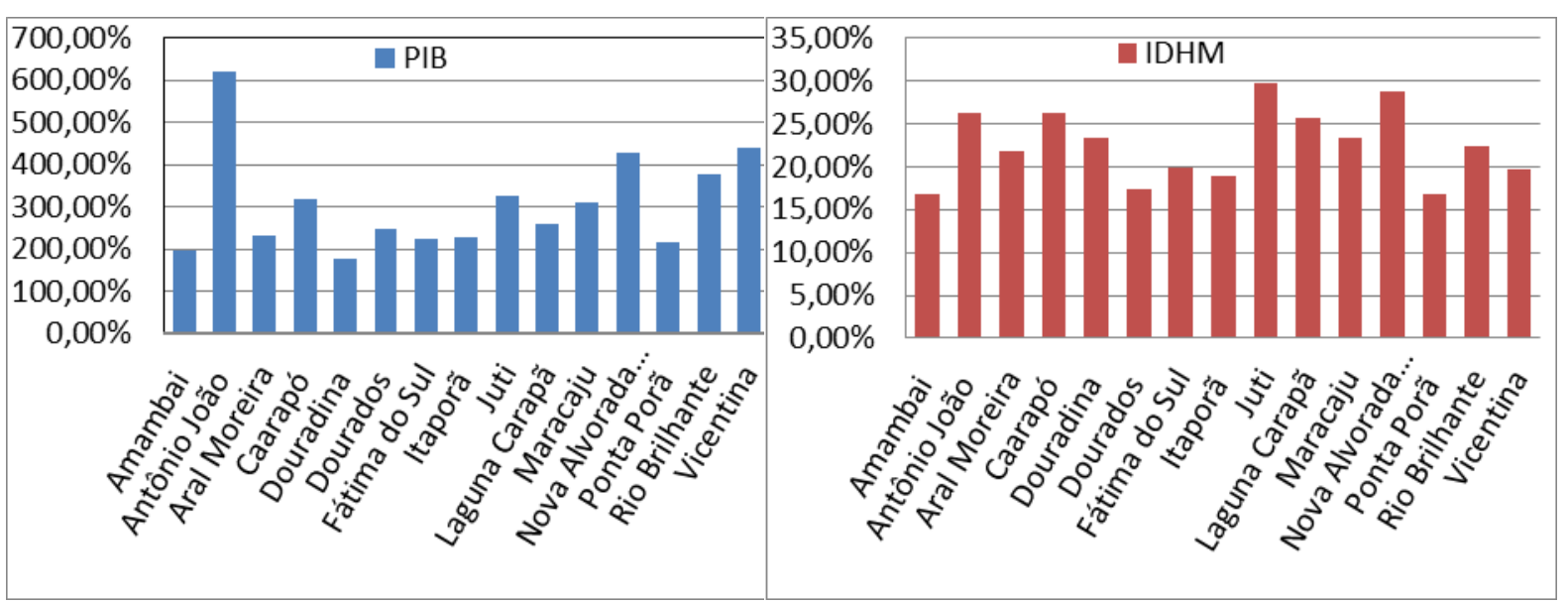

Fonte: SEMAC/MS (2010) e PNUD (2015).

A Figura 2 mostra a disparidade em temos de crescimento do IDHM por componentes, onde se percebe que a educação evoluiu em todos os municípios, mas com esse quesito crescendo de forma bem desproporcional. Juti, Laguna Carapã e Nova Alvorada do Sul foram os municípios que apresentaram a maior evolução do componente educação, enquanto que Dourados, Fátima do Sul e Itaporã foram os que menos evoluíram. Dourados e Fátima do Sul

DRd - Desenvolvimento Regional em debate (ISSNe 2237-9029) 
já possuíam índice acima da média nacional no quesito educação no ano de 2000 , com Dourados mantendo-se acima da média também em 2010, conforme mostra a Tabela 3.

A longevidade foi o componente com maior participação no IDH municipal da microrregião de Dourados. Maracaju foi o município com maior índice de longevidade nos dois anos de referência, 0,792 em 2000, e 0,873 em 2010 (Tabela 3). Porém, há uma intensa disparidade em termos de evolução desse componente no período. Pela Figura 2 percebe-se que Antônio João, Caarapó, Fátima do Sul, Itaporã e Vicentina foram os municípios onde o índice de longevidade mais evoluiu de 2000 a 2010, enquanto que Ponta Porã foi onde a evolução foi menor. Vale lembrar que Ponta Porã já tinha registrado índice de longevidade acima da média nacional em 2000, 0,774, e continuou acima também em 2010, 0,812 (Tabela 3), o que de acordo com a classificação do Programa das Nações Unidas para o Desenvolvimento (PNUD) esse último é um índice considerado muito alto numa escala de $0 \mathrm{a}$ 1 .

Em relação à renda, observa-se, como já mencionado anteriormente, que este componente aparece em segundo lugar em termos de participação no IDHM total dos municípios estudados. Dourados, Maracaju e Nova Alvorada do Sul apresentaram índice superior à média nacional, que foi de 0,739 em 2010 (Tabela 3). No entanto, a exemplo dos demais componentes, há uma forte disparidade em termos de crescimento. Antônio João, Nova Alvorada do Sul, Douradina e Maracaju foram os municípios onde esse componente mais cresceu, enquanto que Laguna Carapã foi o que apresentou o menor desempenho (Figura 2).

Figura 2 - Variação do IDHM nos municípios da microrregião por componente no período de 2000 a 2010

$(\mathrm{em} \%)$

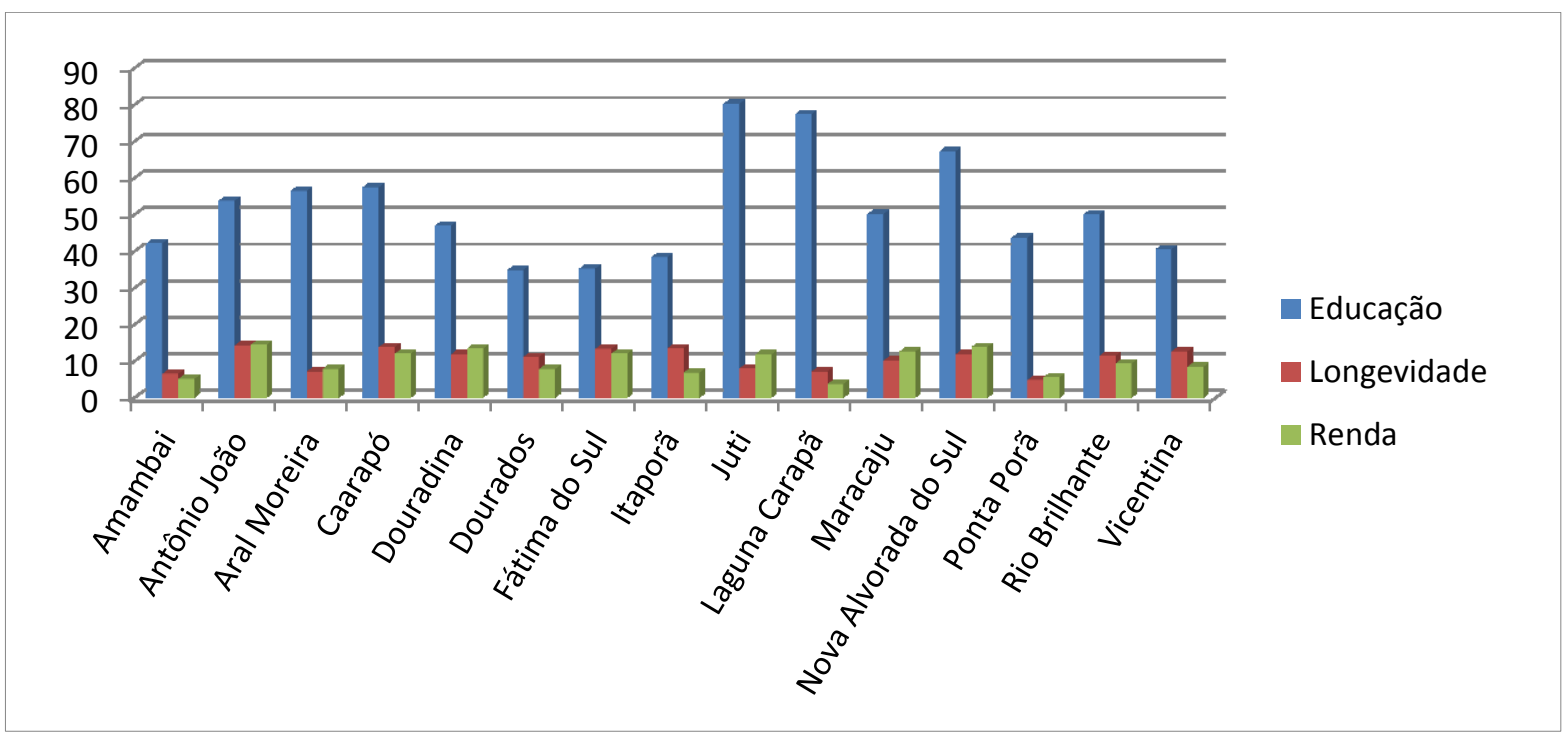

Fonte: SEMAC/MS (2010) e PNUD (2015).

Ao observar os dados das Tabelas 2 e 3, verifica-se que o IDHM total de cada município da microrregião esteve muito relacionado ao IDHM educação. Municípios que detinham IDHM baixo em educação em 2000, mesmo com os componentes longevidade e renda média altos, tanto em 2000 quanto em 2010, apresentaram IDHM total de classificação 
média em 2010, mesmo tendo apresentado evolução significativa do componente educação no período. Esse foi o caso, por exemplo, de municípios como Amambai, Juti, Antônio João, Aral Moreira e Itaporã.

\section{CONSIDERAÇÕES FINAIS}

Os dados apresentados aqui mostraram que o município de Dourados se destaca na microrregião, tanto pela sua participação no PIB, quanto pelo seu elevado Índice de Desenvolvimento Humano Municipal (IDHM). Sua economia é caracterizada pela presença de setores bastante dinâmicos, como é o caso do industrial e de comércio e serviços, e por isso se sobressai aos demais municípios da microrregião. Na visão de Souza (2009), regiões com essas características atraem os fatores de produção com maior facilidade, aumentando seu poder de crescimento, enquanto que as áreas com problemas estruturais tendem a perder populações e capitais.

Em relação ao IDHM, percebe-se que todos os municípios apresentaram evolução, independente de suas dimensões geográficas e dos setores predominantes em suas respectivas economias. No entanto, alguns municípios com pouca expressão, em termos de PIB regional, apresentaram IDHM considerado elevado na comparação com os de maior representatividade. Além disso, os resultados revelaram que a longevidade e a renda média foram os componentes que apresentaram índices mais elevados no cômputo do cálculo do IDHM geral dos municípios, enquanto que a educação apresentou a menor participação, influenciando no resultado.

É importante ressaltar que o nível de desenvolvimento econômico dos municípios estudados, medido pelo IDHM, parece não ter relação com o tamanho de suas respectivas economias. Além disso, as taxas de crescimento econômico não podem ser consideradas a única condição para que um pequeno núcleo social alcance o desenvolvimento. No caso da referida amostra, a educação foi o quesito que influenciou diretamente nos resultados do IDHM total de 2000 e de 2010 , o que deixa claro que a melhoria das condições de vida das pessoas de determinada região não é um fenômeno que ocorre espontaneamente, em decorrência apenas do crescimento, embora esta seja uma condição necessária, por si só não é suficiente.

Assim sendo, afirmar que existe uma relação causal entre crescimento e melhoria das condições de vida das pessoas é controverso. Os frutos do crescimento por si só não se alocam de forma eficiente, sendo necessário políticas públicas que visem promover a equidade social, possibilitando melhorar a oferta de emprego, qualificação profissional, além de saúde $\mathrm{e}$ educação de boa qualidade, bem como segurança pública, lazer, saneamento básico, acesso a tecnologia e a informação, entre outros. Mudança estrutural e contínua desses fatores é condição necessária para que um país ou região alcance o desenvolvimento permanente e adequado.

Todavia, é preciso esclarecer que os resultados aqui apresentados mostram uma realidade peculiar de um conjunto de municípios de uma região especifica em dado período. Dessa forma, não se pode afirmar que os mesmos resultados poderão ser encontrados em

DRd - Desenvolvimento Regional em debate (ISSNe 2237-9029) 
períodos diferentes ou em municípios de outra microrregião. Os diferentes estágios de desenvolvimento encontrado nos municípios da microrregião em estudo, medido pelo IDHM nos dois anos de referência, foram fortemente influenciados pela participação do componente educação. Neste caso, a realização de estudos dessa natureza com outras microrregiões é condição necessária para a obtenção de um diagnóstico mais geral da relação entre crescimento e IDHM.

\section{REFERÊNCIAS}

BASSAN, D. S. Alguns aspectos teóricos do desenvolvimento com o olhar na região do Vale do Paranhana. Revista de Desenvolvimento Econômico, Salvador, v.16, n.29, p. 39-47. jun. 2014.

FEIJÓ, R. Desenvolvimento econômico: modelos, evidências, opções políticas e o caso brasileiro. São Paulo: Atlas, 2007.

FURTADO, C. Desenvolvimento e subdesenvolvimento. São Paulo: Paz e Terra, 1961.

Teoria e Política do Desenvolvimento Econômico. São Paulo: Editora Companhia Nacional, 1967.

GADOTTI, M. Pedagogia da terra. São Paulo: Peirópolis, 2000 (Série Brasil cidadão).

GIL, A. C. Como elaborar projetos de pesquisa. 4. ed. São Paulo: Atlas, 2002.

LEWIS, W. A. A teoria do desenvolvimento econômico. Rio de Janeiro: Zahar, 1960.

MYRDAL, G. Economic theory and under-developed regions. London: Duckworth, 1957.

OLIVEIRA, G. B. de. Uma discussão sobre o conceito de desenvolvimento. Revista da FAE. Curitiba, v.5, n.2, p.37-48, maio/ago. 2002.

PROGRAMA DAS NAÇÕES UNIDAS PARA O DESENVOLVIMENTO - PNUD. Atlas do Desenvolvimento Humano no Brasil 2013 (Com dados dos Censos 1991, 2000 e 2010). Disponível em: $<$ http://www.pnud.org.br/atlas/ranking/Ranking-IDHM-Municipios2010.aspx>. Acesso em: 20 mar. 2015.

SANDRONI, P. Dicionário de economia. São Paulo: Atlas, 1994.

SECRETARIA DE ESTADO DE MEIO AMBIENTE, DO PLANEJAMENTO, DA CIÊNCIA E TECNOLOGIA - SEMAC. Série histórica do PIB municipal 1999-2010. Disponível em: $<$ http://www.uems.br/institucional/pdi/arquivos/47_2013-04-29_15-4508.pdf $>$. Acesso em: 18 mar. 2015.

SIEDENBERG, D. R. Dicionário do Desenvolvimento Regional. Santa Cruz: Edunisc, 2006. 
SIMONSEN, M. H.; CAMPOS, R. de O. A nova economia brasileira. Rio de Janeiro: Editora Biblioteca do Exército, 1975.

SOUZA, N. de J. de. Desenvolvimento econômico. 5. ed. São Paulo: Atlas, 2007.

Desenvolvimento regional. São Paulo: Atlas, 2009.

VASCONCELLOS, M. A. S. de. Economia micro e macro: teoria e exercícios, glossário com 260 principais conceitos econômicos. São Paulo: Atlas, 2000.

Artigo recebido em: 19/08/2015

Artigo aprovado em: 02/04/2016 